\title{
COMPARATIVE STUDY ON PERFORMANCE OF COAGULANTS IN WATER TREATMENT
}

\author{
B.G. Mahendra ${ }^{1}$, Madhusudhan $\mathrm{C}^{2}$ \\ ${ }^{1}$ Associate Professor, ${ }^{2}$ M.Tech Scholar, Department of Civil Engineering, Poojya Doddappa Appa College of \\ Engineering, Gulbarga-585102, Karnataka \\ bgm_pda@yahoo.co.in, masc1942@gmail.com
}

\begin{abstract}
The study on the performance of different coagulants in water treatment was carried out using coagulants such as alum(C1), Poly aluminium chloride $(P A C)(C 2)$ and sodium aluminate $(C 3)$. The performance was studied with respect to turbidity removal, concentration of residual aluminium and comparative cost of coagulants for treatment of Bhima river water. The performances of these coagulants were studied separately as well as mixture of two coagulants in equal proportions. Cl and C2 were mixed to get coagulant mixture (CM1), C1 and C3 were mixed to get CM2, C2 and C3 were mixed to get CM3. The study reviews that the coagulants $C 1$ and CM3 were found to be more efficient with 100\% removal of turbidity at turbidities up to 50 NTU. For higher turbidities above $50 \mathrm{NTU}$, the coagulants C1, C2 and CM1 are found to be more efficient with 100\% turbidity removal. The concentration of residual aluminium is found to be less in CM1 and C2. For turbidities of 200 NTU and 400 NTU with optimum dosages, the concentrations were $0.02 \mathrm{mg} / \mathrm{L}$ and $0.04 \mathrm{mg} / \mathrm{L}$ for CM1 respectively.
\end{abstract}

Keywords: Coagulants, turbidity, residual aluminium.

\section{INTRODUCTION}

The primary source of water is precipitation, which may be available in the form of surface water and ground water. Surface water sources available on the ground are streams, rivers, lakes etc. These sources should have adequate flow of water to be considered as a reliable source of water supply for a town or city. Surface waters generally contain suspended and colloidal solids from land erosion, decaying vegetation, micro-organisms etc. Coarser materials, such as sand and silt, can be eliminated to a considerable extent by plain sedimentation, but finer particles of colloidal must be chemically coagulated to produce larger floc that is removable by subsequent settling and filtration. This treatment of water is very important as polluted water is the main cause for many diseases and may be even worse in spreading an epidemic.

Coagulation is the first process of treatment given to the water in which the chemical compounds called as coagulants are added. The chemistry of coagulation/flocculation consists of three processes - flash mix, coagulation, and flocculation as explained below:-

Flash mixing: - In the flash mixer, coagulant chemicals are added to the water and the water is mixed quickly and violently. The purpose of this step is to evenly distribute the chemicals through the water. Flash mixing typically lasts a minute or less. If the water is mixed for less than thirty seconds, then the chemicals will not be properly mixed into the water. However, if the water is mixed for more than sixty seconds, then the mixer blades will shear the newly forming floc back into small particles.

Coagulation: - After flash mixing, coagulation occurs. During coagulation, the coagulant chemicals neutralize the electrical charges of the fine particles in the water, allowing the particles to come closer together and form large clumps.

Flocculation: - The final step is flocculation. During flocculation, a process of gentle mixing brings the fine particles formed by coagulation into contact with each other. Flocculation typically lasts for about thirty to forty-five minutes. The flocculation basin often has a number of compartments with decreasing mixing speeds as the water advances through the basin. This compartmentalized chamber allows increasingly large floc to form without being broken apart by the mixing blades.

\subsection{Objectives of the Study}

This study has been carried out in the environmental engineering laboratory, civil engineering department of P. D. A college of engineering, Gulbarga, from September-2012 to November-2012 with the following objectives:-

(i) To study the characteristics of Bhima river water.

(ii) To determine the optimum dosage for each coagulant. 
(iii)To study the performance of each coagulant with its optimum dosage and to compare the performance of each coagulant with respect to turbidity removal, residual aluminium and cost of coagulant for treatment

(iv)To study the efficiency of treatment with the combination of two coagulants mixed in equal proportions.

\section{MATERIALS AND METHODOLOGY}

The water samples were collected from Bhima river near the intake structure which is located near the village Saradgi, approximately $16 \mathrm{kms}$ from Gulbarga. The water samples were tested for the characteristics considered as important in coagulation process. Grab sampling technique was adopted to collect the water samples. The materials or aluminium based coagulants used in this study are :-

1) Alum (aluminium sulfate) $\left[\mathrm{Al}_{2}\left(\mathrm{So}_{4}\right)_{3} \cdot 18 \mathrm{H}_{2} \mathrm{O}\right]$

2) Poly aluminium chloride (PAC) $\left[\mathrm{Al}_{12} \mathrm{Cl}_{12}(\mathrm{OH})_{24}\right]$

3) Sodium aluminate $\left(\mathrm{NaAlO}_{2}\right)$

The below given parameters are considered for studying the performance of coagulants:-

1) Optimum dosage(Turbidity removal)

2) Optimum $\mathrm{pH}$

3) Residual aluminium and

4) Cost.

1) Optimum Dosage: Jar tester is used for this test in optimizing the amount of dosage required. Six number of jars were placed and different concentrations of coagulants were added to each beaker. $500 \mathrm{ml} \pm 5 \mathrm{ml}$ were taken in each beaker of $1 \mathrm{~L}$ capacity. The dosing was done without much time difference between the beakers. The paddles of the rotor were maintained at same height for all the beakers. After starting, the flocculator were rotated at a greater speed of $100 \mathrm{rpm}$ for about 2 minutes and were brought down to about $30 \mathrm{rpm}$ and was maintained for 20 minutes. The rotor was stopped and the settling was observed after 20 minutes. Flocs size were observed with naked eye and for turbidity measurement, the sample was pipette out keeping the pipette approximately 2 cms below the surface of sample, then measured on nephelometer.

Coagulant solution: A coagulant solution was prepared by weighing each coagulant to 10 grams and diluting it to 1 litre with distilled water, so that $1 \mathrm{ml}$ of coagulant solution contains $10 \mathrm{mg}$ of coagulant. For a mixture of two coagulants, each coagulant is weighed to 5 grams and mixed together and diluted to 1 litre using distilled water.

2) The wholesome water used for drinking and domestic purpose should have a $\mathrm{pH}$ in the range of 6.5 to 8.5 , which is also the allowable limit. The $\mathrm{pH}$ of the sample was adjusted from 5 to 10 with an interval of 1.0 , and was placed in 6 beakers. From jar tests, dosage concentration which imparted 0 (zero) turbidity was noted and the same is used with varying $\mathrm{pH}$ for each jar. The jar test is repeated and the turbidity is measured and least turbidity yielding $\mathrm{pH}$ is noted and is considered the optimum $\mathrm{pH}$ for the type of coagulant added. This test was carried on water of turbidity 200 NTU with its respective optimum dosage concentration for each coagulant as in table -3 .

3) Residual aluminium: The test was carried on water samples of 200 NTU and 400 NTU with optimum dosage yielding least turbidity respectively.With Eriochrome cyanine $\mathrm{R}$ dye, dilute aluminum solutions buffered to a $\mathrm{pH}$ of 6.0 produce a red to pink complex that exhibits maximum absorption at $535 \mathrm{~nm}$. To compensate for colour and turbidity, the aluminum in one portion of sample is complexed with EDTA to provide a blank. The interference of iron and manganese, two elements commonly found in water when aluminum is present, is eliminated by ascorbic acid.

4) Cost: The cost of treatment for each coagulant is based on the quantity of coagulant required to treat 1 million litre of water with turbidity of 200 NTU and 400 NTU.

\section{RESULTS AND DISCUSSIONS}

The characteristics of water sample such as $\mathrm{pH}$, total solids, alkalinity and turbidity were tested and are given in table -1 .

Table1. Characteristics of water samples collected near the intake structure.

\begin{tabular}{|c|c|c|c|c|}
\hline \multirow{2}{*}{ Sample no. } & \multicolumn{4}{|c|}{ Characteristics } \\
\cline { 2 - 5 } & $\mathbf{p H}$ & Total solids, $\mathbf{~ m g / L}$ & Alkalinity, $\mathbf{~ m g / L}$ & Turbidity, NTU \\
\hline 1 & 6.92 & 410 & 28 & 135 \\
\hline 2 & 7.09 & 396 & 30 & 132 \\
\hline 3 & 7.00 & 453 & 26 & 141 \\
\hline 4 & 7.16 & 512 & 34 & 159 \\
\hline 5 & 7.29 & 498 & 34 & 168 \\
\hline 6 & 7.42 & 560 & 35 & 156 \\
\hline 7 & 7.31 & 489 & 35 & 162 \\
\hline 8 & 7.52 & 518 & 35 & \\
\hline
\end{tabular}




\begin{tabular}{|c|c|c|c|c|}
\hline 9 & 7.39 & 546 & 33 & 165 \\
\hline 10 & 7.48 & 540 & 32 & 165 \\
\hline 11 & 7.35 & 512 & 33 & 160 \\
\hline 12 & 7.43 & 521 & 32 & 160 \\
\hline Mean & $\mathbf{7 . 2 8}$ & $\mathbf{4 9 6 . 2 5}$ & $\mathbf{3 2 . 2 5}$ & $\mathbf{1 5 4 . 8 3}$ \\
\hline
\end{tabular}

The water sample collected from the river was tested on the same day of collection so as to get consistency in the characteristics of the sample. The optimum dosage of coagulant for different turbidities was studied using the jar test apparatus. The turbidity of the clear water after jar tests were found out with the help of nephelometer. The results of water samples having turbidities 50 NTU, 100 NTU, 200 NTU and 400 NTU with their efficiency of turbidity removal and cost of coagulant are tabulated in tables -2 . Optimum dosage results are shown in figures -1 to 4 .

Table2 Optimum dosage and cost of coagulants for treating 1 million litres of river water

\begin{tabular}{|c|c|c|c|c|c|c|c|c|c|c|c|c|}
\hline \multirow[b]{2}{*}{ Coagulant } & \multicolumn{3}{|c|}{$50 \mathrm{NTU}$} & \multicolumn{3}{|c|}{$100 \mathrm{NTU}$} & \multicolumn{3}{|c|}{$200 \mathrm{NTU}$} & \multicolumn{3}{|c|}{$400 \mathrm{NTU}$} \\
\hline & $\begin{array}{l}\text { Qty } \\
\text { in } \\
\text { Kgs }\end{array}$ & $\begin{array}{c}\text { Cost } \\
\text { in } \\
\text { Rs }\end{array}$ & $\begin{array}{l}\mathrm{E} \\
\text { in } \\
\%\end{array}$ & $\begin{array}{l}\text { Qty } \\
\text { in } \\
\text { Kgs }\end{array}$ & $\begin{array}{c}\text { Cost } \\
\text { in } \\
\text { Rs }\end{array}$ & $\begin{array}{l}\mathrm{E} \\
\text { in } \\
\%\end{array}$ & $\begin{array}{l}\text { Qty } \\
\text { in } \\
\text { Kgs }\end{array}$ & $\begin{array}{c}\text { Cost } \\
\text { in } \\
\text { Rs }\end{array}$ & $\begin{array}{l}\mathrm{E} \\
\text { in } \\
\%\end{array}$ & $\begin{array}{l}\text { Qty } \\
\text { in } \\
\text { Kgs }\end{array}$ & $\begin{array}{c}\text { Cost } \\
\text { in } \\
\text { Rs }\end{array}$ & $\begin{array}{l}\mathrm{E} \\
\text { in } \\
\%\end{array}$ \\
\hline $\mathrm{C} 1$ & 60 & 1458 & 100 & 120 & 2916 & 100 & 240 & 5832 & 100 & 380 & 9234 & 100 \\
\hline $\mathrm{C} 2$ & 40 & 5400 & 100 & 100 & 13500 & 100 & 200 & 27000 & 100 & 340 & 45900 & 100 \\
\hline $\mathrm{C} 3$ & 100 & 11880 & 98 & 280 & 33264 & 100 & 460 & 54648 & 98 & 740 & 87912 & 99 \\
\hline CM1 & 40 & 3186 & 100 & 60 & 4779 & $\overline{100}$ & 140 & 11151 & 100 & 260 & 20709 & 100 \\
\hline CM2 & 50 & 3577 & 100 & 160 & 11448 & 98 & 340 & 24327 & 100 & 580 & 41499 & 100 \\
\hline CM3 & 40 & 2862 & 100 & 100 & 12675 & 100 & 240 & 30456 & 100 & 400 & 50760 & 100 \\
\hline
\end{tabular}

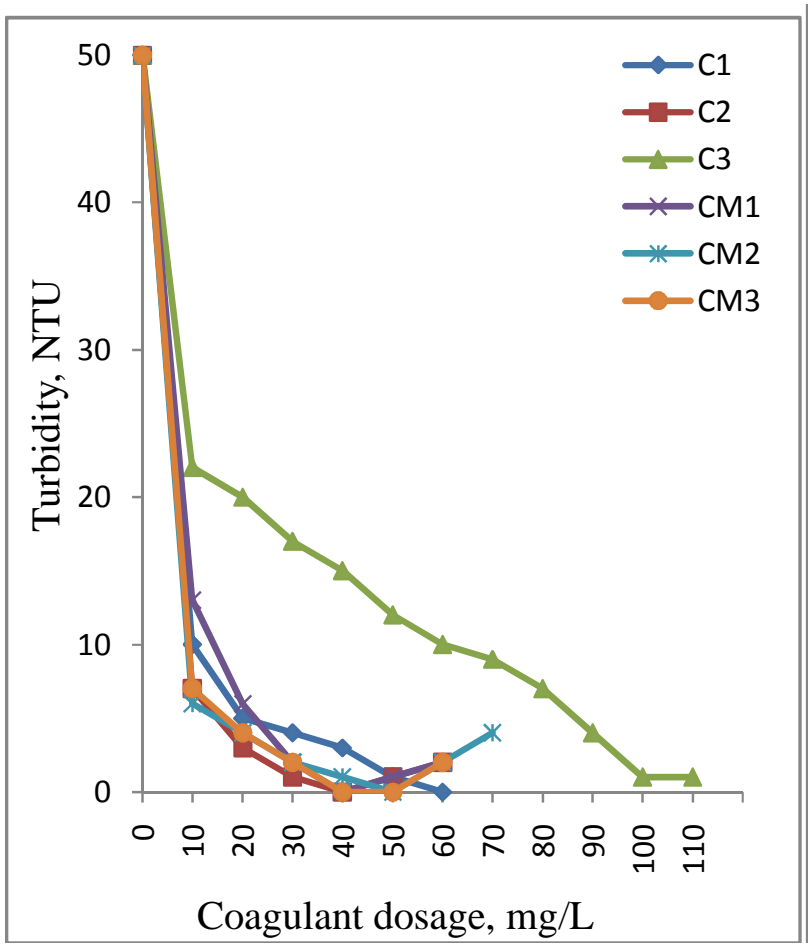

Fig1. Showing the optimum dosage of Coagulants for turbidity of $50 \mathrm{NTU}$

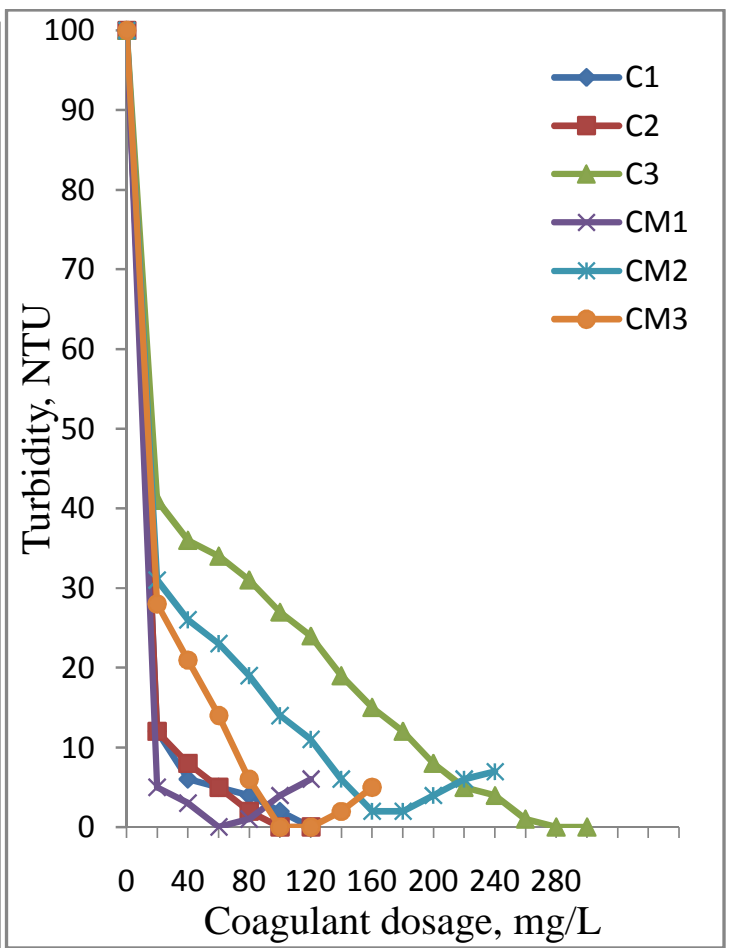

Fig2 Showing the optimum dosage of Coagulants for turbidity of 100 NTU 


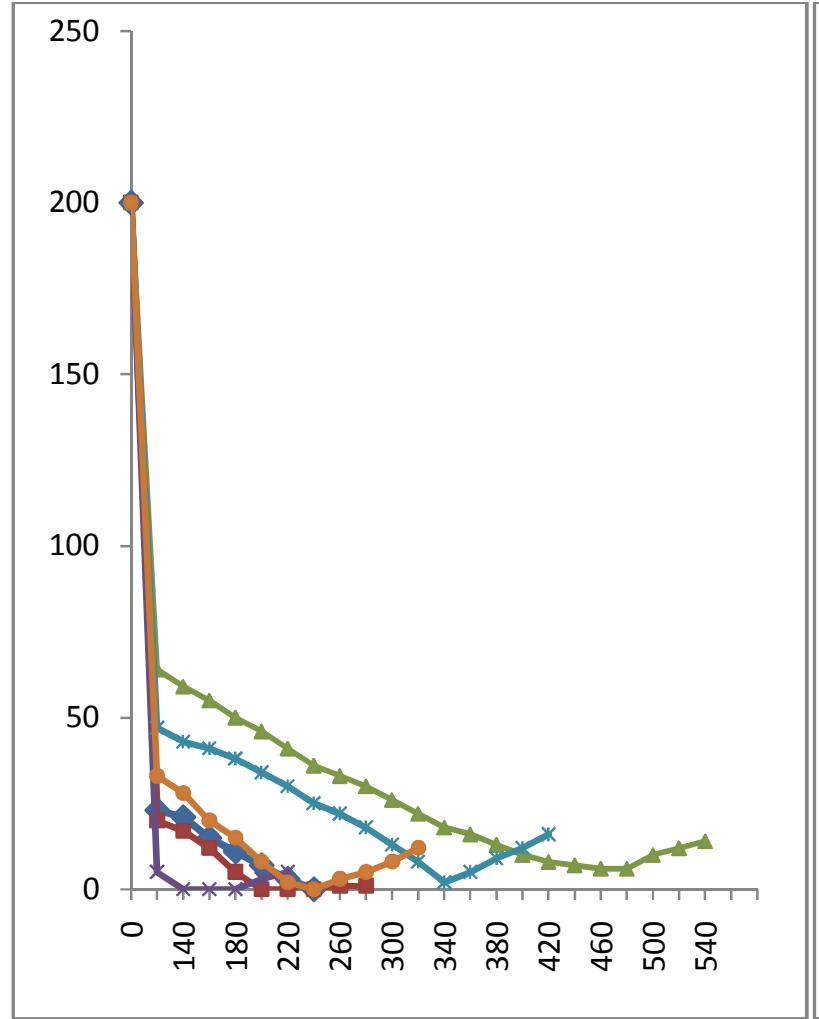

Fig3. Showing the optimum dosage of coagulants for turbidity of 200 NTU.

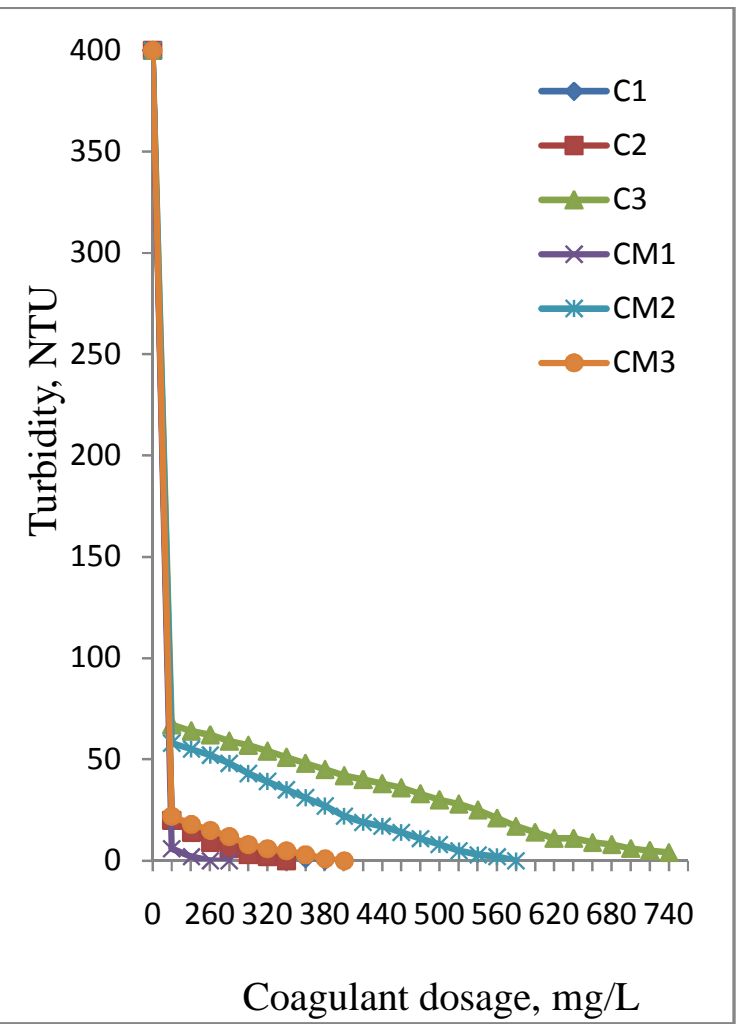

Fig4 Showing the optimum dosage of coagulants for turbidity of 400 NTU.

Table3. Optimum pH for a turbidity of 200 NTU.

\begin{tabular}{|c|c|c|c|c|c|c|}
\hline $\mathrm{pH}$ & $\begin{array}{c}\mathrm{C} 1 \\
\text { Dosage-240 } \\
\mathrm{mg} / \mathrm{L}\end{array}$ & $\begin{array}{c}\mathrm{C} 2 \\
\text { Dosage-420 } \\
\mathrm{mg} / \mathrm{L}\end{array}$ & $\begin{array}{c}\mathrm{C} 3 \\
\text { Dosage-460 } \\
\mathrm{mg} / \mathrm{L}\end{array}$ & $\begin{array}{c}\mathrm{CM} \\
\text { Dosage-140 } \\
\mathrm{mg} / \mathrm{L}\end{array}$ & $\begin{array}{c}\text { CM2 } \\
\text { Dosage-340 } \\
\mathrm{mg} / \mathrm{L}\end{array}$ & $\begin{array}{c}\text { CM3 } \\
\text { Dosage-240 } \\
\mathrm{mg} / \mathrm{L}\end{array}$ \\
\hline 5 & 01 & 00 & 01 & 00 & 12 & 12 \\
\hline 6 & 00 & 00 & 04 & 00 & 06 & 04 \\
\hline 7 & 00 & 00 & 08 & 00 & 01 & 03 \\
\hline 8 & 00 & 00 & 08 & 00 & 00 & 03 \\
\hline 9 & 04 & 02 & 09 & 00 & 00 & 02 \\
\hline 10 & 05 & 02 & 09 & 02 & 01 & 02 \\
\hline
\end{tabular}




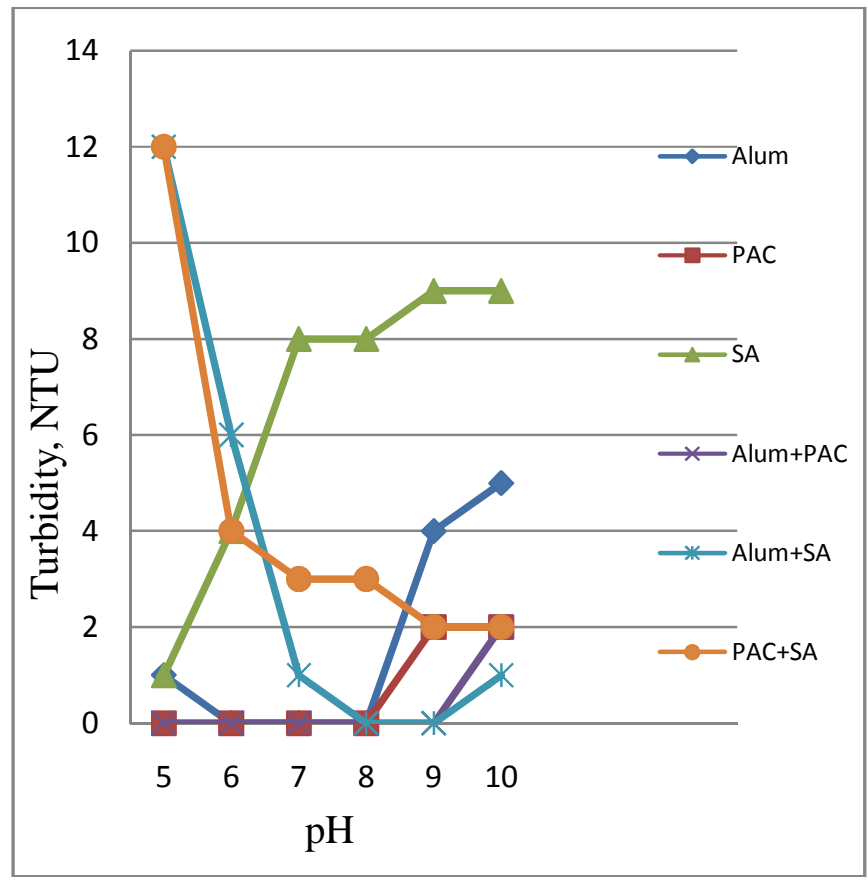

Fig5. Showing the turbidity vs $\mathrm{pH}$ results for a turbidity of 200 NTU.

Residual aluminium: The test was carried on water samples of 200 NTU and 400 NTU with optimum dosage yielding least turbidity. The concentrations of residual aluminium for optimum dosages is given in table -4 and shown in figure -6 .

Table4. Residual aluminium concentration with optimum dosages

\begin{tabular}{|c|c|c|c|c|c|c|}
\hline \multirow{2}{*}{ Coagulants } & \multicolumn{3}{|c|}{ Turbidity $-200 \mathrm{NTU}$} & \multicolumn{3}{c|}{ Turbidity $-400 \mathrm{NTU}$} \\
\cline { 2 - 7 } & $\begin{array}{c}\text { Dosage } \\
\mathrm{mg} / \mathrm{L}\end{array}$ & $\mathrm{pH}$ & $\begin{array}{c}\mathrm{Al} \\
\mathrm{mg} / \mathrm{L}\end{array}$ & $\begin{array}{c}\text { Dosage } \\
\mathrm{mg} / \mathrm{L}\end{array}$ & $\mathrm{pH}$ & $\begin{array}{c}\mathrm{Al} \\
\mathrm{mg} / \mathrm{L}\end{array}$ \\
\hline $\mathrm{C} 1$ & 240 & 7.0 & 0.07 & 380 & 7.0 & 0.09 \\
\hline $\mathrm{C} 2$ & 200 & 7.0 & 0.03 & 340 & 7.0 & 0.05 \\
\hline $\mathrm{C} 3$ & 460 & 5.0 & 0.18 & 740 & 5.0 & 0.24 \\
\hline $\mathrm{CM} 1$ & 140 & 7.0 & 0.02 & 260 & 7.0 & 0.04 \\
\hline $\mathrm{CM} 2$ & 340 & 8.0 & 0.12 & 580 & 8.0 & 0.18 \\
\hline $\mathrm{CM} 3$ & 240 & 9.0 & 0.11 & 400 & 9.0 & 0.12 \\
\hline
\end{tabular}

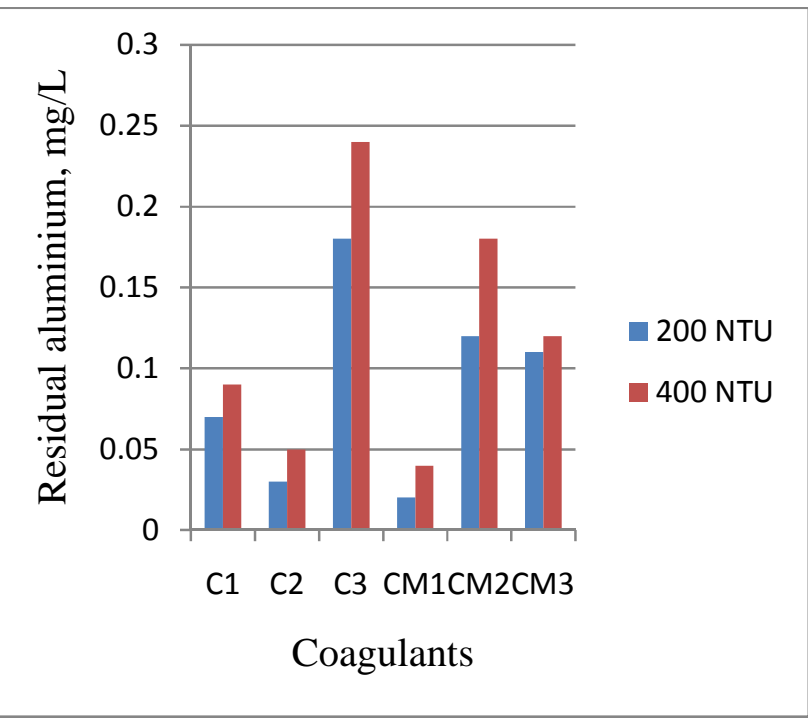

Fig6. Showing the residual aluminium concentration for turbidity of 200 and 400 NTU

Coagulant CM1 is having the least aluminium concentration in treated water when coagulated at optimum dosage concentration for turbidities of 200 and 400 NTU. The residual aluminium concentration was $0.02 \mathrm{mg} / \mathrm{L}$ and 0.04 $\mathrm{mg} / \mathrm{L}$ with $\mathrm{CM} 1$ for turbidities of 200 and 400 NTU respectively.

Cost: The cost of the alum(C1) is far more lesser than poly aluminium chloride $(\mathrm{C} 2)$ and sodium aluminate $(\mathrm{C} 3)$. The cost of coagulants is given in the table -5 . The cost per $\mathrm{Kg}$ of coagulant, for CM1, CM2 and CM3 were computed and were found to be still higher than $\mathrm{C} 1$. The quantity and cost of coagulant for treating 1 million litres(ML) of river water is summarized in table -2 and from this summary we can see that even with least dosage the cost of treatment is high for coagulants $\mathrm{C} 2, \mathrm{C} 3, \mathrm{CM} 2, \mathrm{CM} 3$ and $\mathrm{CM} 1$ to that of $\mathrm{C} 1$.

Table5. Cost of coagulants per unit weight

\begin{tabular}{|c|c|}
\hline Coagulants & $\begin{array}{c}\text { Cost per Kg in } \\
\text { Rupees }\end{array}$ \\
\hline Alum(C1) & 24.3 \\
\hline $\begin{array}{c}\text { Poly aluminium } \\
\text { chloride(C2) }\end{array}$ & 135.0 \\
\hline Sodium aluminate(C3) & 118.8 \\
\hline $\begin{array}{c}\text { Alum + poly aluminium } \\
\text { chloride(CM1) }\end{array}$ & 79.65 \\
\hline $\begin{array}{c}\text { Alum + Sodium } \\
\text { aluminate(CM2) }\end{array}$ & 71.55 \\
\hline $\begin{array}{c}\text { Poly aluminium chloride }+ \\
\text { Sodium aluminate(CM3) }\end{array}$ & 126.9 \\
\hline
\end{tabular}




\section{CONCLUSIONS}

On analyzing the results based on the laboratory experiments conducted, the following conclusions are drawn.

1) The characteristics of water sample collected from Bhima river were found to be $\mathrm{pH}-7.28$, total solids $-496.25 \mathrm{mg} / \mathrm{L}$, alkalinity $-32.25 \mathrm{mg} / \mathrm{L}$ and turbidity -155 NTU.

2) Coagulant CM1 is found to be good coagulant for all the turbidity values with least dosage to remove $100 \%$ turbidity.

3) CM1 has the wider range of $\mathrm{pH}$ suitability and works satisfactorily over a $\mathrm{pH}$ range of 5.0 to 9.0 over other coagulants considered for the study.

4) The residual aluminium concentration in treated water is less when CM1 is used, ie 0.02 and 0.04 $\mathrm{mg} / \mathrm{L}$ for turbidities 200 and 400 NTU respectively with optimum dosages.

5) The cost per unit weight of CM1 is less than both $\mathrm{C} 2$ and $\mathrm{C} 3$, but more than $\mathrm{C} 1$. The cost of coagulant required for treating 1 million litres of water is least for $\mathrm{C} 1$ even with its higher dosage requirement over CM1.

\section{REFERENCES}

[1] APHA, AWWA, Standard Methods for Examination of Water and Wastewater, $19^{\text {th }}$ Edition. Prepared and Published by American Public Health Association, American Water Works Association, Water Pollution Control Federation (1995)

[2] Drinking water standards, Bureau of Indian Standards, IS 10500-1991.

[3] FPSDW- (Federal-Provincial Sub-committee on Drinking water). 2001. Summary of guidelines for Canadian drinking water quality.

[4] U.S.EPA- (United States Environmental Protection Agency). 1999. Enhanced coagulation and enhanced precipitative softening guidance manual.EPA 815-R99-012, $237 \mathrm{p}$.

[5] WHO (2004). Guidelines for drinking-water quality, 3rd ed., World Health Organization, Geneva. 